Article

\title{
Exosomal microRNA Differential Expression in Plasma of Young Adults with Chronic Mild Traumatic Brain Injury and Healthy Control
}

Rany Vorn ${ }^{1}{ }^{\mathbb{D}}$, Maiko Suarez ${ }^{2}$, Jacob C. White ${ }^{3}$, Carina A. Martin ${ }^{1} \mathbb{D}$, Hyung-Suk Kim ${ }^{1}$, Chen Lai ${ }^{1}$, Si-Jung Yun ${ }^{4}$, Jessica M. Gill ${ }^{5,6}$ and Hyunhwa Lee ${ }^{7, *(D)}$

Citation: Vorn, R.; Suarez, M.; White, J.C.; Martin, C.A.; Kim, H.-S.; Lai, C.; Yun, S.-J.; Gill, J.M.; Lee, H. Exosomal microRNA Differential Expression in Plasma of Young Adults with Chronic Mild Traumatic Brain Injury and Healthy Control. Biomedicines 2022, 10, 36. https://doi.org/ 10.3390/biomedicines10010036

Academic Editors: Kumar Vaibhav, Meenakshi Ahluwalia and Pankaj Gaur

Received: 12 October 2021

Accepted: 21 December 2021

Published: 24 December 2021

Publisher's Note: MDPI stays neutral with regard to jurisdictional claims in published maps and institutional affiliations.

Copyright: (c) 2021 by the authors. Licensee MDPI, Basel, Switzerland. This article is an open access article distributed under the terms and conditions of the Creative Commons Attribution (CC BY) license (https:// creativecommons.org/licenses/by/ $4.0 /)$.
1 National Institute of Nursing Research, National Institutes of Health, Bethesda, MD 20814, USA; rany.vorn@nih.gov (R.V.); carina.martin@nih.gov (C.A.M.); kimhy@mail.nih.gov (H.-S.K.); laichi@mail.nih.gov (C.L.)

2 School of Medicine, University of Nevada, Las Vegas, NV 89102, USA; suarem2@unlv.nevada.edu

3 College of Liberal Arts, University of Nevada, Las Vegas, NV 89154, USA; whitej31@unlv.nevada.edu

4 Yotta Biomed, LLC, Bethesda, MD 20817, USA; sijungyun@yottabiomed.com

5 School of Nursing and Medicine, Johns Hopkins University, Baltimore, MD 21205, USA; JessicaGill@jhu.edu

6 Center for Neuroscience and Regenerative Medicine, Uniformed Services University of the Health Science, Bethesda, MD 20814, USA

7 School of Nursing, University of Nevada, Las Vegas, NV 89154, USA

* Correspondence: hyunhwa.lee@unlv.edu

\begin{abstract}
Chronic mild traumatic brain injury (mTBI) has long-term consequences, such as neurological disability, but its pathophysiological mechanism is unknown. Exosomal microRNAs (exomiRNAs) may be important mediators of molecular and cellular changes involved in persistent symptoms after mTBI. We profiled exosomal microRNAs (exomiRNAs) in plasma from young adults with or without a chronic $\mathrm{mTBI}$ to decipher the underlying mechanisms of its long-lasting symptoms after mTBI. We identified 25 significantly dysregulated exomiRNAs in the chronic mTBI group $(n=29$, with 4.48 mean years since the last injury) compared to controls $(n=11)$. These miRNAs are associated with pathways of neurological disease, organismal injury and abnormalities, and psychological disease. Dysregulation of these plasma exomiRNAs in chronic mTBI may indicate that neuronal inflammation can last long after the injury and result in enduring and persistent post-injury symptoms. These findings are useful for diagnosing and treating chronic mTBIs.
\end{abstract}

Keywords: mild traumatic brain injury; microRNA; exomiRNA; exosome

\section{Introduction}

More than 5.5 million mild traumatic brain injuries (mTBI) are reported annually in the United States [1]. In most individuals with mTBI, the symptoms can resolve within days to weeks; yet for 10-15\% of mTBI patients, symptoms last longer than three months and can result in disability [2,3]. Repetitive mTBIs, which usually contribute to chronic mTBI with unresolved and persistent symptoms, are common in athletes and military personnel, and these individuals have a higher risk of chronic neurologic impairment [4,5]. Over $25 \%$ of individuals with long-term mTBI consequences are not able to return to work 1-year post-injury [1]. Chronic mTBI becomes a major health concern due to life-long disabilities and long-term consequences that severely compromise the affected individuals' quality of life [6-8]. mTBI costs each patient $\$ 36,000$ for rehabilitation [9] and the entire nation nearly \$17 billion each year [10]. However, molecular mechanisms critical to chronic mTBI symptoms are currently unknown.

MicroRNAs (miRNAs) are small, single-stranded non-coding RNAs that regulate gene expression at the post-transcriptional level of target messenger RNA [11,12]. Circulating miRNAs are found in biofluids such as serum, plasma, saliva, and cerebrospinal fluid. They 
are stable and resistant to RNase digestion because they are encapsulated into extracellular vesicles called exosomes [13]. Exosomal miRNAs (exomiRNAs) in biofluids are potential biomarker candidates for diagnosis and prognosis of neurodegenerative disorders [14] such as Alzheimer's disease (AD), Parkinson's disease, and TBI due to their stability, and have the ability to regulate hundreds of target genes [13,15]. Dysregulated miRNAs may also reflect changes at the molecular level after the TBI [16].

We performed this comparative research to investigate differential expression of plasma exomiRNAs in the participants exhibiting chronic mTBIs such as repetitive head injuries compared with healthy controls. Identified plasma exomiRNAs were analyzed using bioinformatic knowledge-based Ingenuity Pathways Analysis (IPA) to understand the molecular pathway associated with plasma exomiRNAs after injury.

\section{Materials and Methods}

\subsection{Study Protocol}

Participants were recruited from the protocols granted by the Biomedical Institutional Review Board Committee at the University of Nevada, Las Vegas (UNLV) (Protocols No. 1048342 \& 975928). Voluntary participants of this study were recruited via flyers and email advertisements addressing members of the UNLV campus, including the Military and Veteran Services Center and the Las Vegas community. They were voluntary participants aged 18 years or older with or without a self-reported history of mTBI. Those with mTBI histories were exposed to closed head trauma with loss of consciousness for less than $30 \mathrm{~min}$ and post-traumatic amnesia for less than $24 \mathrm{~h}$, following the mTBI diagnosis guidelines defined by the American Congress of Rehabilitation Medicine [17]. The Neurobehavioral Symptom Inventory (NSI) and the Rivermead Post-Concussion Symptoms Questionnaire (RPQ) were used to assess the participant's symptom experiences following mTBI. The NSI consists of 22 symptoms on a Likert scale of 0 to 4 ( $0=$ none, $1=$ mild, $2=$ moderate, $3=$ severe, and $4=$ very severe), with a total sum score range of 0 to 88 , and can be divided into three subscales affective, cognitive, and somatic/somatosensory [18]. The NSI is known to be reliable and valid for measuring post-concussive symptoms in TBI patients [19]. The RPQ is a 16-item questionnaire with a Likert scale of 0 to $4(0=$ none, $1=$ mild, $2=$ moderate, $3=$ severe, and $4=$ very severe) with a total sum score range of 0 to 64 . The RPQ exhibits excellent internal consistency in TBI patients at all levels of severity-mild, moderate, and severe TBI [20]. Higher total scores of NSI and RPQ indicate more severe symptoms. Subjects with a previous or current diagnosis of neuropsychiatric disease (e.g., multiple sclerosis, attention deficit hyperactivity disorder, mood disorders, substance use disorders, etc.) or who were currently on any prescription drugs were excluded.

\subsection{Plasma Collection}

A phlebotomist drew blood in $4 \mathrm{~mL}$ blood collection tubes via venipuncture from each participant in the designated lab. Each $4 \mathrm{~mL}$ participant blood sample was centrifuged at $1900 \times g$ at $4{ }^{\circ} \mathrm{C}$ for $10 \mathrm{~min}$. Once centrifuged, the plasma was carefully aspirated into DNase- and RNase-free Eppendorf tubes without disturbing the underlying buffy coat layer where most of the white blood cells were collected. The plasma samples were centrifuged in the Eppendorf tubes at $3000 \times g$ at $4{ }^{\circ} \mathrm{C}$ for an additional $15 \mathrm{~min}$ to remove cellular debris. The cleared supernatant was transferred to polypropylene cryovial tubes and stored at $-70{ }^{\circ} \mathrm{C}$ in the UNLV Applied Biomedical Research Lab until purification.

\subsection{ExomiRNA Purification}

Plasma samples were removed from $-70{ }^{\circ} \mathrm{C}$ storage, thawed, and centrifuged at $3000 \times g$ for $5 \mathrm{~min}$ to remove cryoprecipitates. The supernatant was transferred to a new tube to begin total RNA purification. Plasma exosomal total RNA purification was performed using the exoRNeasy Serum Plasma kit (Cat. \# 77064, Qiagen, Hilden, Germany) according to the manufacturer's protocol. In short, up to $1 \mathrm{~mL}$ or $4 \mathrm{~mL}$ of plasma was used, depending on the use of the Midi or Maxi kit, respectively. Both kits yielded similar output 
volumes. Plasma samples were washed with various buffer solutions provided by the manufacturer. Once washed, $700 \mu \mathrm{L}$ of QIAzol lysis solution was added and centrifuged at $5000 \times g$ for $5 \mathrm{~min}$ to create a lysate solution. Then chloroform was combined with the lysate and centrifuged at $12,000 \times g$ for $15 \mathrm{~min}$, after which the aqueous phase containing RNA was isolated. Total RNA purification was thereafter carried out using the RNeasy MinElute spin column, additional buffer solutions, and RNase-free water. Purified RNA samples were shipped overnight on dry ice to the Intramural Research Program laboratory at the National Institute of Nursing Research (NINR), in the National Institutes of Health (NIH) for additional processing.

\subsection{ExomiRNA Profiling}

Plasma exomiRNA analysis was performed in a nCounter MAX/FLEX Analysis System using nCounter ${ }^{\circledR}$ Human v3 miRNA Expression Panels (NanoString Technologies, Seattle, WA, USA) that contained 798 unique miRNA probes. Probes for housekeeping genes such as ribosomal protein L10, beta-actin, beta-2-microglobulin, glyceraldehyde 3-phosphate dehydrogenase, and ribosomal protein L19, as well as endogenous miRNAs that were incorporated in the code sets, were used for analysis in addition to positive and negative controls. The complete RNA samples were prepared and run according to the manufacturer's protocol. Counts of the reporter probes were obtained using the nCounter Digital Analyzer. Raw data were analyzed by nSolver Software version 4.0 (NanoString Technologies), and code count normalization was carried out by calculating the geometric mean of the ligation factors. Multiple testing correction with Benjamini-Hochberg's False Discovery Rate (FDR; $p<0.100)$ was used as a cutoff for the differential dysregulation with statistical significance.

\subsection{Network Analysis}

The biological pathways associated with dysregulated plasma exomiRNAs were determined using Ingenuity Pathways Analysis (IPA) software (Ingenuity Systems Inc., Redwood City, CA, USA). All differentially expressed plasma exomiRNAs with FDR correction of less than 0.100 were uploaded into IPA for core pathway analysis. MicroRNA Target Filters were then used to identify the plasma exomiRNA-regulated mRNAs and enriched pathways. The Ingenuity Expert Findings, Ingenuity ExpertAssist Findings, miRecords, TarBase, and TargetScan Human source were used to assess gene target predictions, and miRWalk web tools were used for confirmation.

\subsection{Statistical Analysis}

Statistical analysis was conducted using SPSS version 28.0.0.0 (IBM Corp., Armonk, NY, USA). Demographic and clinical characteristics were compared between groups using Chi-square $\left(\chi^{2}\right)$ and an independent sample $t$-test. The significance level was set at 0.05 in all tests.

\section{Results}

\subsection{Demographics of the Study Population}

A total of 40 participants, including 29 individuals with a history of mTBI and 11 without, participated in the study. The study participants were aged 19 to 36 years (24.8 \pm 5.219$)$. More than half of the study participants were female $(52.5 \%)$ or White $(57.5 \%)$. There were no statistical differences based on demographic characteristics, including age, gender, race, and BMI, between the two groups. In the chronic mTBI group $(n=29), 65.5 \%$ reported having more than 1 injury (41.4\% with 2 or 3 injuries and $27.6 \%$ with 4 or more injuries), and the average number was 2.55 injuries $(S D=1.325)$. The average number of years since the last injury was 4.48 years $(S D=5.000)$. Only 1 participant in the $\mathrm{mTBI}$ group reported that they experienced both a brief loss of consciousness and post-traumatic amnesia resulting from the injury (3.4\%). Two additional participants with a history of mTBI reported having post-traumatic amnesia $(6.9 \%)$. The most common causes of injuries were sports-related 
activities (48.3\%) (e.g., boxing, mixed martial arts [MMA] training, skating, football, etc.), followed by head hitting hard objects (e.g., sharp edge, metal materials, etc.) (20.7\%), and high-level falls $(17.2 \%)$. A few cases were related to military service activities $(10.3 \%)$ or car accidents $(3.4 \%)$. The demographics and clinical characteristics of the participants are presented in Table 1.

Table 1. Demographic and Clinical Characteristics of Chronic mTBI and Healthy Control Participants $(n=40)$.

\begin{tabular}{|c|c|c|c|c|c|}
\hline Characteristic & $\begin{array}{l}\text { Overall } \\
(n=40)\end{array}$ & $\begin{array}{l}\text { Chronic mTBI } \\
\quad(n=29)\end{array}$ & $\begin{array}{l}\text { Control } \\
(n=11)\end{array}$ & $\chi^{2}$ or $t$ & $p$ \\
\hline \multicolumn{6}{|l|}{ Demographic } \\
\hline Age, Mean (SD) & $24.80(5.22)$ & $25.59(5.36)$ & $22.73(4.41)$ & 1.576 & 0.123 \\
\hline \multicolumn{6}{|l|}{ Gender, $n(\%)$} \\
\hline Males & $19(47.5)$ & $15(51.7)$ & $4(36.4)$ & 0.755 & 0.488 \\
\hline Females & $21(52.5)$ & $14(48.3)$ & $7(63.6)$ & & \\
\hline Weight (kg), Mean (SD) & $69.83(14.64)$ & $70.18(13.29)$ & $68.91(18.45)$ & 0.243 & 0.810 \\
\hline Height (cm), Mean (SD) & $167.52(10.94)$ & $168.26(10.48)$ & $165.56(12.38)$ & 0.691 & 0.494 \\
\hline BMI, Mean (SD) & $24.74(3.77)$ & $24.65(3.40)$ & $24.98(4.81)$ & -0.247 & 0.807 \\
\hline \multicolumn{6}{|l|}{ Ethnicity/Race, $n(\%)$} \\
\hline Hispanic & $6(15.0)$ & $4(13.8)$ & $2(18.2)$ & 1.038 & 0.904 \\
\hline White & $23(57.5)$ & $17(58.6)$ & $6(54.5)$ & & \\
\hline Black & $1(2.5)$ & $1(3.4)$ & $0(0.0)$ & & \\
\hline Asian & $8(20.0)$ & $6(20.7)$ & $2(18.2)$ & & \\
\hline Other & $2(5.0)$ & $1(3.4)$ & $1(9.1)$ & & \\
\hline \multicolumn{6}{|l|}{ Handedness, $n(\%)$} \\
\hline Right & $37(92.5)$ & $27(93.1)$ & $10(90.9)$ & 0.055 & 1.000 \\
\hline Left & $3(7.5)$ & $2(6.9)$ & $1(9.1)$ & & \\
\hline \multicolumn{6}{|l|}{ Education, $n(\%)$} \\
\hline In college & $31(77.5)$ & $22(75.9)$ & $9(81.8)$ & 0.162 & 1.000 \\
\hline In graduate school & $9(22.5)$ & $7(24.1)$ & $2(18.2)$ & & \\
\hline \multicolumn{6}{|l|}{ Marital Status, $n(\%)$} \\
\hline Single & $36(90.0)$ & $26(89.7)$ & $10(90.9)$ & 0.412 & 0.814 \\
\hline Married & $4(10.0)$ & $3(10.3)$ & $1(9.1)$ & & \\
\hline \multicolumn{6}{|l|}{ Employment Status, $n(\%)$} \\
\hline Yes & $30(75.0)$ & $23(79.3)$ & $7(63.6)$ & 1.045 & 0.418 \\
\hline No & $10(25.0)$ & $6(20.7)$ & $4(36.4)$ & & \\
\hline \multicolumn{6}{|l|}{ Clinical } \\
\hline RPQ Total, Mean (SD) & $12.58(12.42)$ & $16.76(12.14)$ & $1.55(2.07)$ & 6.505 & $<0.001$ \\
\hline NSI Total, Mean (SD) & $15.43(14.06)$ & $19.86(13.91)$ & $3.73(4.65)$ & 5.489 & $<0.001$ \\
\hline Somatic/Sensory, Mean (SD) & $5.58(5.81)$ & $7.34(5.83)$ & $0.91(1.81)$ & 5.304 & $<0.001$ \\
\hline Cognitive, Mean (SD) & $2.75(2.88)$ & $3.55(2.89)$ & $0.64(1.50)$ & 4.156 & $<0.001$ \\
\hline Affective, Mean (SD) & $7.10(6.42)$ & $8.97(6.56)$ & $2.18(1.94)$ & 5.023 & $<0.001$ \\
\hline \multicolumn{6}{|l|}{ Injury Characteristics } \\
\hline $\begin{array}{l}\text { Number of Injuries, Mean } \\
\text { (SD) }\end{array}$ & & $2.55(1.33)$ & $\mathrm{N} / \mathrm{A}$ & & \\
\hline Single Injury & & $9(31.0)$ & $\mathrm{N} / \mathrm{A}$ & & \\
\hline Multiple Injuries & & $20(69.0)$ & $\mathrm{N} / \mathrm{A}$ & & \\
\hline $\begin{array}{l}\text { Time since the last Injury } \\
\text { (years), Mean (SD) }\end{array}$ & & $4.48(5.00)$ & $\mathrm{N} / \mathrm{A}$ & & \\
\hline \multicolumn{6}{|l|}{ Mechanism of Injury, $n(\%)$} \\
\hline Sports-related & & $14(48.3)$ & $\mathrm{N} / \mathrm{A}$ & & \\
\hline Head hit & & $6(20.7)$ & $\mathrm{N} / \mathrm{A}$ & & \\
\hline High-level Falls & & $5(17.2)$ & $\mathrm{N} / \mathrm{A}$ & & \\
\hline Military-related & & $3(10.3)$ & $\mathrm{N} / \mathrm{A}$ & & \\
\hline Car accident & & $1(3.4)$ & $\mathrm{N} / \mathrm{A}$ & & \\
\hline
\end{tabular}




\subsection{Differential Expression of Plasma ExomiRNAs}

We assessed the expression levels of plasma exomiRNAs in the chronic mTBI group compared to control subjects. After normalization with ligation factors, we identified 25 plasma exomiRNAs differentially expressed in chronic mTBI compared to healthy control with an adjusted $p$-value $<0.100$. Among them, 4 plasma exomiRNAs were upregulated, and 21 plasma exomiRNAs were downregulated in the chronic mTBI group compared with the control (Table 2).

Table 2. Dysregulated ExomiRNAs following Chronic mTBI.

\begin{tabular}{|c|c|c|c|}
\hline Probe Name & Target Sequence & $\log 2 F C$ & Adjusted $p$-Value \\
\hline $\begin{array}{l}\text { Upregulated } \\
\text { hsa-miR-520e }\end{array}$ & AAAGUGCUUCCUUUUUGAGGG & 0.98 & 0.03 \\
\hline hsa-miR-499b-3p & AACAUCACUGCAAGUCUUAACA & 0.83 & 0.01 \\
\hline hsa-miR-520b & AAAGUGCUUCCUUUUAGAGGG & 0.43 & 0.04 \\
\hline hsa-miR-4488 & AGGGGGCGGGCUCCGGCG & 0.42 & 0.03 \\
\hline \multicolumn{4}{|l|}{ Downregulated } \\
\hline hsa-miR-625-5p & AGGGGGAAAGUUCUAUAGUCC & -0.96 & 0.08 \\
\hline hsa-miR-421 & AUCAACAGACAUUAAUUGGGCGC & -1.39 & 0.08 \\
\hline hsa-miR-664a-3p & UAUUCAUUUAUCCCCAGCCUACA & -1.43 & 0.08 \\
\hline hsa-miR-28-3p & CACUAGAUUGUGAGCUCCUGGA & -1.49 & 0.04 \\
\hline hsa-miR-125a-5p & UCCCUGAGACCCUUUAACCUGUGA & -2.10 & 0.04 \\
\hline hsa-miR-222-3p & AGCUACAUCUGGCUACUGGGU & -2.14 & 0.09 \\
\hline hsa-miR-140-5p & CAGUGGUUUUACCCUAUGGUAG & -2.17 & 0.07 \\
\hline hsa-miR-98-5p & UGAGGUAGUAAGUUGUAUUGUU & -2.32 & 0.09 \\
\hline hsa-miR-148a-3p & UCAGUGCACUACAGAACUUUGU & -2.63 & 0.06 \\
\hline hsa-miR-423-5p & UGAGGGGCAGAGAGCGAGACUUU & -2.65 & 0.09 \\
\hline hsa-miR-107 & AGCAGCAUUGUACAGGGCUAUCA & -2.75 & 0.07 \\
\hline hsa-miR-181a-5p & AACAUUCAACGCUGUCGGUGAGU & -2.81 & 0.09 \\
\hline hsa-miR-374a-5p & UUAUAAUACAACCUGAUAAGUG & -2.86 & 0.09 \\
\hline hsa-miR-340-5p & UUAUAAAGCAAUGAGACUGAUU & -2.87 & 0.07 \\
\hline hsa-miR-29b-3p & UAGCACCAUUUGAAAUCAGUGUU & -2.95 & 0.05 \\
\hline hsa-miR-191-5p & CAACGGAAUCCCAAAAGCAGCUG & -3.03 & 0.08 \\
\hline hsa-miR-199a-3p & ACAGUAGUCUGCACAUUGGUUA & -3.13 & 0.05 \\
\hline hsa-miR-126-3p & UCGUACCGUGAGUAAUAAUGCG & -3.13 & 0.09 \\
\hline hsa-miR-23a-3p & AUCACAUUGCCAGGGAUUUCC & -3.36 & 0.04 \\
\hline hsa-miR-142-3p & UGUAGUGUUUCCUACUUUAUGGA & -3.39 & 0.07 \\
\hline hsa-miR-223-3p & UGUCAGUUUGUCAAAUACCCCA & -3.62 & 0.04 \\
\hline
\end{tabular}

ExomiRNA, exosomal microRNAs.

\subsection{Pathway Analysis}

Pathway analysis using IPA revealed that dysregulated plasma exomiRNAs are related to neurological disease, organismal injury and abnormalities, and psychological disorders (Table 3). Top network analysis showed that these plasma exomiRNAs are associated with connective tissue disorders, inflammatory disease, organismal injury, and network abnormalities. The specific plasma exomiRNAs associated in this network (Figure 1) were hsa-miR-103-3p (synonym to hsa-miR-107), hsa-miR-126a-5p, hsa-miR-140-5p, hsa-miR142-3p, hsa-miR-199a-3p, hsa-miR-221-3p (synonym to hsa-miR-222-3p), hsa-miR-23a-3p, hsa-miR-291a-3p (synonym to hsa-miR-520e), hsa-miR-374b-5p, hsa-miR-423-5p, hsa-miR625-5p, hsa-miR-664-3p. These plasma exomiRNAs are directly or indirectly associated with acyl-CoA synthetase long-chain family member 6 (ACSL6), EPH receptor B6 (EPHB6), growth arrest specific 5 (GAS5), GNAS antisense RNA 1 (Gnasas1), hepatocellular carcinoma upregulated EZH2-associated long non-coding RNA (HEIH), homeobox A11 (HOXA11), phosphatase and tensin homolog (PTEN), resolvin D1, ribosomal protein S 15 (RPS15), tumor necrosis factor (TNF), vasohibin 1 (VASH1), and vascular endothelial growth factor A (VEGFA). Dysregulated exomiRNAs targeting mRNA associated with neuroinflammation pathways are presented in Figure 2 and Supplementary Table S1. 
Table 3. Top IPA Biological Functions and Disease Pathway.

\begin{tabular}{|c|c|c|}
\hline Diseases and Disorders & $p$-Value Range & Number of Molecules \\
\hline Neurological disease & $4.58 \times 10^{-2}-4.85 \times 10^{-14}$ & 14 \\
\hline Organismal injury and abnormality & $4.95 \times 10^{-2}-4.85 \times 10^{-14}$ & 23 \\
\hline Psychological disease & $4.58 \times 10^{-2}-4.85 \times 10^{-14}$ & 13 \\
\hline Cancer & $4.95 \times 10^{-2}-7.96 \times 10^{-13}$ & 21 \\
\hline Reproductive system disease & $4.85 \times 10^{-2}-1.49 \times 10^{-12}$ & 20 \\
\hline Molecular and Cellular Functions & $p$-Value Range & Number of Molecules \\
\hline Cell cycle & $4.02 \times 10^{-2}-2.46 \times 10^{-6}$ & 4 \\
\hline Cellular movement & $4.88 \times 10^{-2}-2.46 \times 10^{-6}$ & 12 \\
\hline Cellular development & $4.47 \times 10^{-2}-5.25 \times 10^{-6}$ & 12 \\
\hline Cellular growth and proliferation & $4.47 \times 10^{-2}-5.25 \times 10^{-6}$ & 12 \\
\hline Cell death and survival & $3.99 \times 10^{-2}-8.71 \times 10^{-5}$ & 11 \\
\hline $\begin{array}{c}\text { Physiological System Development } \\
\text { and Function }\end{array}$ & $p$-Value Range & Number of Molecules \\
\hline Organismal development & $3.74 \times 10^{-2}-6.45 \times 10^{-9}$ & 11 \\
\hline Organismal functions & $8.69 \times 10^{-4}-7.19 \times 10^{-4}$ & 2 \\
\hline Tissue morphology & $8.90 \times 10^{-5}-1.72 \times 10^{-3}$ & 3 \\
\hline $\begin{array}{l}\text { Hematological system development and } \\
\text { functions }\end{array}$ & $4.47 \times 10^{-2}-1.98 \times 10^{-3}$ & 6 \\
\hline Immune cell trafficking & $2.74 \times 10^{-2}-1.98 \times 10^{-3}$ & 2 \\
\hline
\end{tabular}

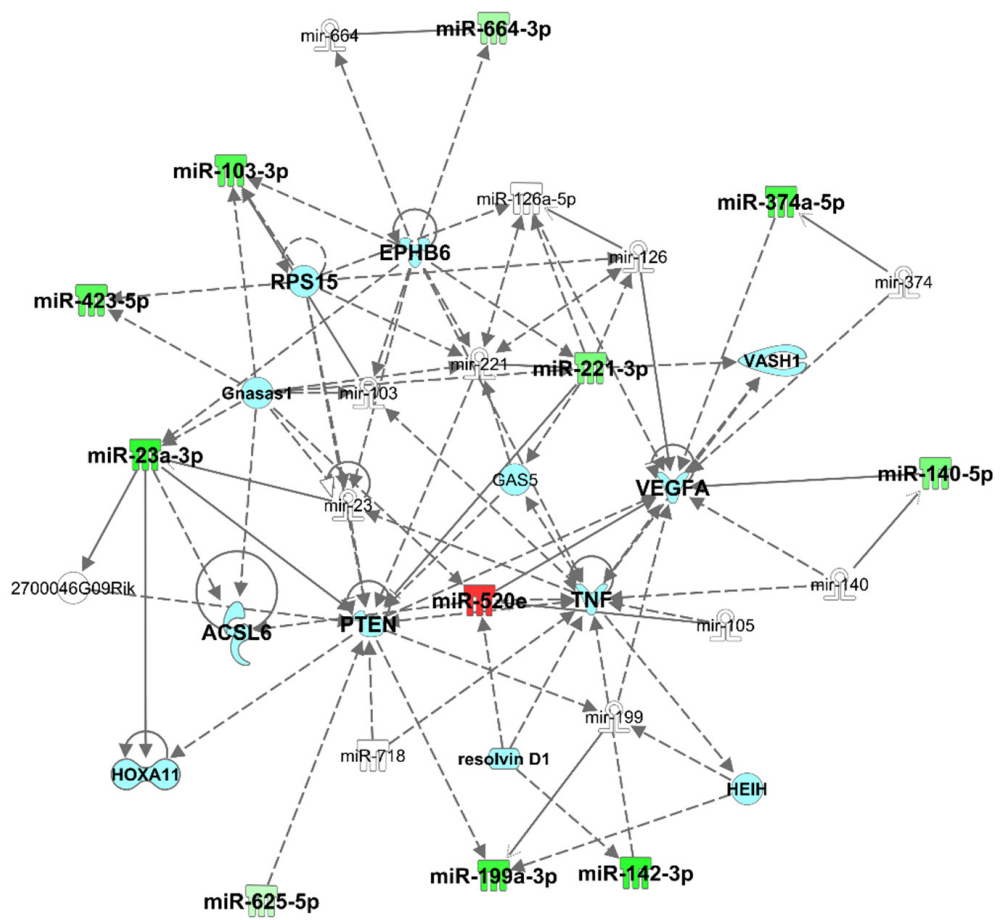

Figure 1. Top network identified by Ingenuity Pathway Analysis (IPA) for chronic mild traumatic brain injury (mTBI) versus control: Connective Tissue Disorders, Inflammatory Disease, and Organismal Injury and Abnormalities. Green indicates genes that are downregulated, and red indicates genes that are upregulated, where increased color saturation represents more extreme down- or upregulated in the dataset. Solid lines represent direct interactions, nontargeting interactions, or correlations between chemicals, proteins, or RNA. Dotted lines represented indirect interaction. Arrowed lines represent activation, causation, expression, localization, membership, modification, molecular cleavage, phosphorylation, protein-DNA interactions, protein-TNA interaction, binding regulation, and transcription. Shapes represent molecule type (double circle $=$ complex $/$ group; square $=$ cytokine; diamond = enzyme; inverted triangle = kinase; triangle = phosphatase; oval = transcription regulator; trapezoid = transporter; circle = other). Reprinted from Ingenuity Pathway Analysis under a CC BY 4.0 license, with permission from QIAGEN Silicon Valley, original copyright 2000-2021. 


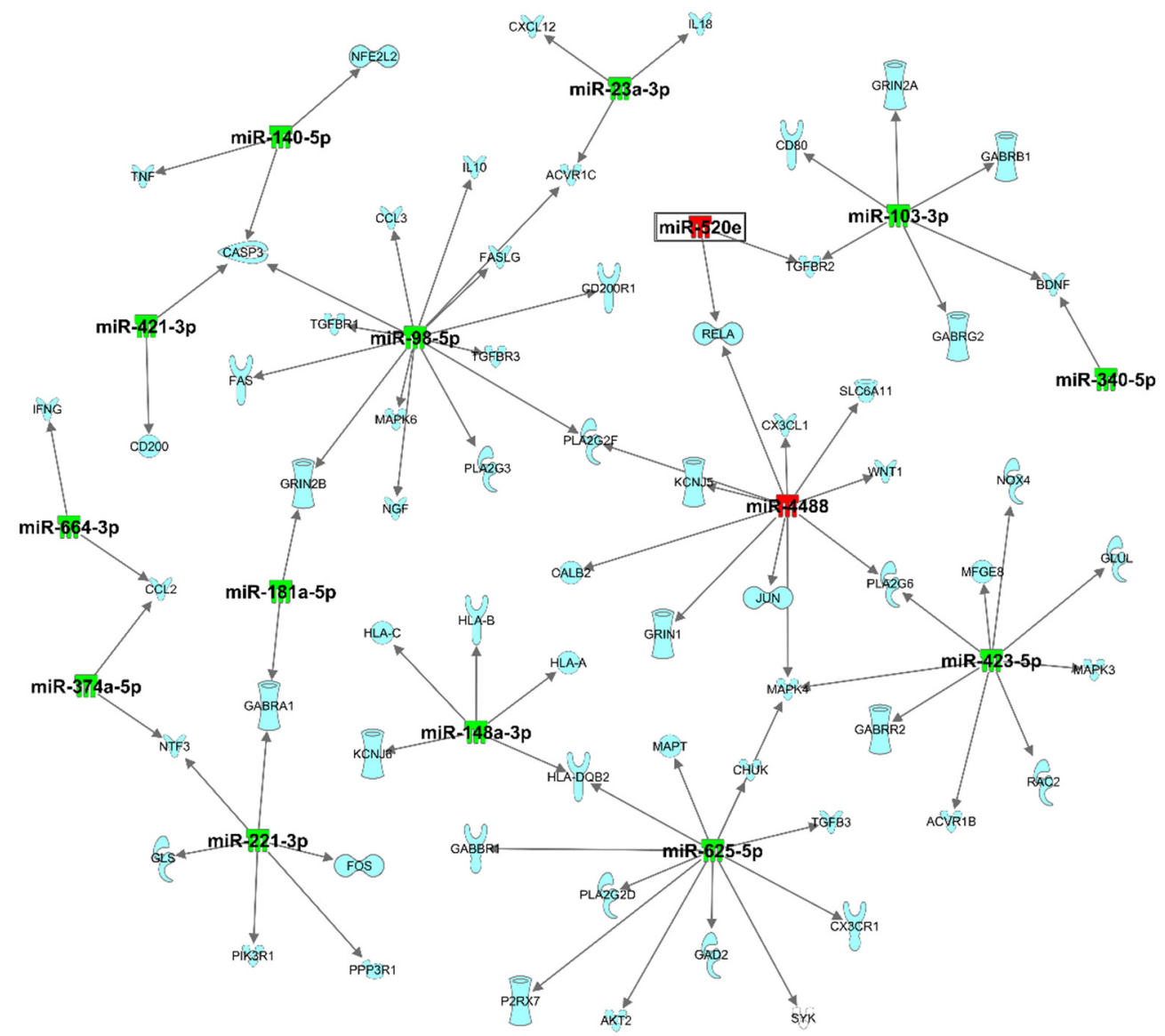

Figure 2. Target filter analysis of dysregulated exomiRNA targeting mRNA associated with neuroinflammation pathways. Green indicates genes that are downregulated, and red indicates genes that are upregulated, where increased color saturation represents more extreme down- or upregulated in the dataset. Reprinted from Ingenuity Pathway Analysis under a CC BY 4.0 license, with permission from QIAGEN Silicon Valley, original copyright 2000-2021.

\section{Discussion}

In this study, we reported on several dysregulated plasma exomiRNAs in chronic mTBIs compared to healthy controls. We used multiplexed nCounter miRNA assays developed by NanoString technology to quantify low expression levels of exomiRNAs in plasma. The nCounter system is more sensitive than microarray for quantification of gene expression, with more accurate and reliable detection of very low expression levels [21]. The current study identified 25 dysregulated exomiRNAs that were associated with chronic mTBI. Pathway analysis showed that 14 plasma exomiRNAs were related to neurological disease, 23 plasma exomiRNAs were related to organismal injury and abnormalities, and 13 plasma exomiRNAs were related to psychological disease. Our results offered insights into the molecular mechanisms underlying injuries to brain function after mTBI.

In recent years, the role of miRNAs is indicated in the early diagnosis and progression of diseases including cancer, AD, and Parkinson's disease [13-16]. Because they are short, miRNAs move freely across the blood-brain barrier (BBB) into the peripheral circulation, which can reflect changes in brain function due to a TBI [11,12,22]. Disruption of the BBB after injury promotes systemic inflammatory factors, neurotoxins, and pathogens into the brain and leads to neuronal damage [23]. Pathway analysis revealed that these plasma exomiRNAs are closely associated with VEGFA. VEGF is predominantly expressed in endothelial cells and plays an essential role in vascular development and neuroprotection [24,25]. Increased peripheral circulating levels of VEGF have been linked to alterations in BBB permeability following the infiltration of immune cells after a TBI $[23,26]$. Elevated 
concentrations of plasma VEGF and TNF- $\alpha$ protein were reported previously in mTBI patients [27].

Microglia and astrocytes are key mediators of neuroinflammation in the central nervous system (CNS) because of the release of inflammatory cytokines after brain injury. Ongoing neuroinflammation was observed when microglia became activated, even after 1 to 18 years of a single moderate-to-severe TBI [28-30]. Inflammatory cytokines were elevated in the plasma of mTBI patients within $24 \mathrm{~h}$ of injury [31], even up to a year later [32]. Many of the plasma exomiRNAs identified in our study were consistently found in the exosome and associated with neuroinflammation [5]. Previous studies reported that downregulation of hsa-miR-223-3p was associated with sporadic amyotrophic lateral sclerosis patients $[33,34]$. Downregulation of mitochondria-associated miR-142-3p was reported in a preclinical model of severe TBI [35]. As confirmed by target miRNAs and pathway analyses, these plasma exomiRNAs were found in brain cells and highly expressed in microglia [35], which are involved in neuroinflammation signaling and the glutamate signaling pathway through targeting the SLC1A3 gene [36,37].

Our targeted analysis showed that downregulated hsa-miR-223-3p, has-miR-29b-3p, and has-miR-107, present in the chronic mTBI group, targeted the NFIA gene. NFIA is a member of the transcription factor nuclear factor I (NFI) family (NFIB, NFIC, and NFIX) and plays an essential role in neural development in the CNS [38]. NFIA is expressed in mature astrocytes and plays an essential role in retrieving forms of memory. A recent preclinical study showed that loss of NFIA inhibited neurotransmission and memory loss [39]. The major neurotransmitter in the CNS includes gamma-aminobutyric acid (GABA) and glutamate, which are involved in synapse plasticity, learning, and memory formation [40]. The targeted analysis showed that dysregulated has-miR-107 targeted the GABA receptor subunit gamma1 (GABRG1) and GABA A receptor subunit beta1 (GABRB1) genes. Mutation in the $\mathrm{GABA}_{\mathrm{A}}$ receptor was associated with a neurological disorder and dysregulated $\mathrm{GABA}_{\mathrm{A}}$ subunit gene expression as observed in the preclinical TBI model [41,42].

Downregulation of hsa-miR-107 (synonym to hsa-miR-103-3p) in our current study is consistent with previous findings [5]. miR-107 was reported as a synaptic region marker involved in the synaptogenesis signaling pathway targeting the synuclein gamma (SNCG), synaptotagmin 2 (SYT2), SYT6, and brain-derived neurotrophic factor (BDNF) genes (Supplementary Figure S1) [43]. SNCG genes are predominantly expressed in neuronal tissue and play an important role in synaptic plasticity and dopamine regulation [44]. Overexpressed SNCG was associated with neurodegenerative disease pathogenesis in clinical and preclinical studies [45-47]. In addition to neurodegeneration, overexpressed SNCG was linked to poor prognosis in cancer and a preclinical TBI model [48,49]. A previous study showed that miR-107 was downregulated in AD and enhanced disease progression by regulating the beta-site amyloid precursor cleaving enzyme1 (BACE1) gene [50]. BACE1 is predominantly expressed in neurons and is responsible for the generation of amyloidbeta [51]. Overall, our findings suggest that chronic mTBI is associated with exomiRNA dysregulation, which may impact neurodegenerative disorders.

A major strength of this study is that the cases and controls were well matched. Although this study provides biological molecular insights into chronic mTBI, it was constrained by a small sample size. The majority of our sample population consisted of White individuals, which limits the genetic diversity and generalizability to all chronic mTBI populations. We were also unable to differentiate plasma exomiRNAs expression in single or multiple injuries due to our small sample size. Additional studies in a larger cohort should investigate the effect of single and repetitive injury on exomiRNAs expression level. Repetitive injury is a major risk for developing chronic neurological symptoms or impaired behaviors [52]. Future studies with larger cohorts will validate our observations that plasma exomiRNAs are associated with symptom deficits following brain injury.

In summary, chronic mTBI is associated with dysregulated exomiRNAs in plasma. These exomiRNAs were associated with inflammation processes that potentially link to neu- 
rological disability. Our data may aid in understanding the pathophysiological mechanism underlying the long-term impacts of mTBI.

Supplementary Materials: The following are available online at https:/ / www.mdpi.com/article/10 .3390 / biomedicines10010036/s1, Figure S1: Target filter analysis of dysregulated exomiRNA targeting mRNA associated with neuroinflammation and synaptogenesis pathways. Table S1: microRNA Target Filter (IPA).

Author Contributions: H.L. conceptualized and supervised the overall project. H.L. and R.V. contributed to designing the experiment, interpreting the data, and writing the manuscript. H.L., M.S. and J.C.W. administered the project, recruited human subjects, and collected data. M.S. and J.C.W. processed and purified plasma exomiRNAs. R.V. conducted exomiRNA profiling. R.V. and H.L. analyzed and interpreted the data. M.S., J.C.W., C.A.M., H.-S.K., S.-J.Y., C.L. and J.M.G. reviewed and edited the manuscript. H.L. and J.M.G. acquired funding for the project. All authors have read and agreed to the published version of the manuscript.

Funding: This research was funded by the School of Nursing of the University of Nevada, Las Vegas (UNLV; 2221-257-554G), the American Psychiatric Nurses Association (APNA; GR009253), and the National Institute of Nursing Research (NINR) Intramural Program. The research was also supported by the UNLV 2017-2020 Top Tier Doctoral Graduate Research Assistantship and the UNLV School of Medicine Medical Student Research Program.

Institutional Review Board Statement: The study was conducted according to the guidelines of the Declaration of Helsinki and approved by the Institutional Review Board Committee of the University of Nevada, Las Vegas (Protocols No. 1048342 \& 975928, approved on 25 May 2017, and 28 June 2017).

Informed Consent Statement: Informed consent was obtained from all subjects involved in the study.

Data Availability Statement: Data that support the findings of this study are available upon reasonable request from any qualified investigator to the corresponding author.

Acknowledgments: This study was supported by the UNLV School of Nursing, 2017-2020 UNLV Faculty Top Tier Doctoral Graduate Research Assistantship Program, and the 2019 UNLV School of Medicine Research Program for Medical Students. Blood samples were collected via venipuncture by 2 Registered Nurses, Hannah Greilish and Florence Chipondaminga. The publication fees for this article were supported by the UNLV University Libraries Open Article Fund. Figures 1 and 2 (Top networks) were reprinted from Ingenuity Pathway Analysis under a CC BY 4.0 license, with permission from QIAGEN Silicon Valley, original copyright 2000-2021.

Conflicts of Interest: The authors declare no conflict of interest. The funders had no role in designing the study, in the collection, analyses, or interpretation of data, in the writing of the manuscript or the decision to publish the results.

\section{References}

1. Langlois, J.A.; Rutland-Brown, W.; Wald, M.M. The epidemiology and impact of traumatic brain injury: A brief overview. J. Head Trauma Rehabil. 2006, 21, 375-378. [CrossRef]

2. Dikmen, S.; Machamer, J.; Temkin, N. Mild traumatic brain injury: Longitudinal study of cognition, functional status, and post-traumatic symptoms. J. Neurotrauma 2017, 34, 1524-1530. [CrossRef]

3. Frieden, T.R.; Houry, D.; Baldwin, G. Traumatic Brain Injury in the United States: Epidemiology and Rehabilitation. CDC NIH Rep. Congr. 2015, 1-74. Available online: https://www.cdc.gov/traumaticbraininjury/pdf/tbi_report_to_congress_epi_and_ rehab-a.pdf (accessed on 7 August 2021).

4. Lehman, E.J.; Hein, M.J.; Baron, S.L.; Gersic, C.M. Neurodegenerative causes of death among retired national football league players. Neurology 2012, 79, 1970-1974. [CrossRef] [PubMed]

5. Devoto, C.; Lai, C.; Qu, B.X.; Guedes, V.A.; Leete, J.; Wilde, E.; Walker, W.C.; Diaz-Arrastia, R.; Kenney, K.; Gill, J. Exosomal MicroRNAs in Military Personnel with Mild Traumatic Brain Injury: Preliminary Results from the Chronic Effects of Neurotrauma Consortium Biomarker Discovery Project. J. Neurotrauma 2020, 37, 2482-2492. [CrossRef] [PubMed]

6. Seabury, S.A.; Gaudette, É; Goldman, D.P.; Markowitz, A.J.; Brooks, J.; McCrea, M.A.; Okonkwo, D.O.; Manley, G.T.; Adeoye, O.; Badjatia, N.; et al. Assessment of Follow-up Care After Emergency Department Presentation for Mild Traumatic Brain Injury and Concussion: Results From the TRACK-TBI Study. JAMA Netw. Open 2018, 1, e180210. [CrossRef] [PubMed] 
7. Smith, D.H.; Johnson, V.E.; Stewart, W. Chronic neuropathologies of single and repetitive TBI: Substrates of dementia? Nat. Rev. Neurol. 2013, 9, 211-221. [CrossRef] [PubMed]

8. Centers for Disease Control and Prevention. Surveillance Report of Traumatic Brain Injury-Related Emergency Department Visits, Hospitalizations, and Deaths—United States, 2014. 2019. Available online: https://www.cdc.gov/traumaticbraininjury/pdf/ TBI-Surveillance-Report-FINAL_508.pdf (accessed on 7 August 2021).

9. McGregor, K.; Pentland, B. Head injury rehabilitation in the U.K.: An economic perspective. Soc. Sci. Med. 1997, 45, 295-303. [CrossRef]

10. Centers for Disease Control and Prevention (CDC). Report to Congress on Mild Traumatic Brain Injury in the United States: Steps to Prevent a Serious Public Health Problem; CDC: Atlanta, GA, USA, 2003.

11. Friedman, R.C.; Farh, K.K.H.; Burge, C.B.; Bartel, D.P. Most mammalian mRNAs are conserved targets of microRNAs. Genome Res. 2009, 19, 92-105. [CrossRef] [PubMed]

12. Peng, Y.; Croce, C.M. The role of MicroRNAs in human cancer. Signal Transduct. Target. Ther. 2016, 1, 15004. [CrossRef]

13. Mitchell, P.S.; Parkin, R.K.; Kroh, E.M.; Fritz, B.R.; Wyman, S.K.; Pogosova-Agadjanyan, E.L.; Peterson, A.; Noteboom, J.; O’Briant, K.C.; Allen, A.; et al. Circulating microRNAs as stable blood-based markers for cancer detection. Proc. Natl. Acad. Sci. USA 2008, 105, 10513-10518. [CrossRef] [PubMed]

14. Watson, C.N.; Belli, A.; Di Pietro, V. Small non-coding RNAs: New class of biomarkers and potential therapeutic targets in neurodegenerative disease. Front. Genet. 2019, 10, 364. [CrossRef]

15. Xi, Y.; Nakajima, G.; Gavin, E.; Morris, C.G.; Kudo, K.; Hayashi, K.; Ju, J. Systematic analysis of microRNA expression of RNA extracted from fresh frozen and formalin-fixed paraffin-embedded samples. RNA 2007, 13, 1668-1674. [CrossRef]

16. Atif, H.; Hicks, S.D. A Review of MicroRNA Biomarkers in Traumatic Brain Injury. J. Exp. Neurosci. 2019, 13, 1-12. [CrossRef] [PubMed]

17. Kay, T.; Harrington, D.; Adams, R. Definition of mild traumatic brain injury: American congress of rehabilitation medicine. J. Head Trauma Rehabil. 1993, 8, 74-85. [CrossRef]

18. Caplan, L.J.; Ivins, B.; Poole, J.H.; Vanderploeg, R.D.; Jaffee, M.S.; Schwab, K. The structure of postconcussive symptoms in 3 us military samples. J. Head Trauma Rehabil. 2010, 25, 447-458. [CrossRef]

19. King, P.R.; Donnelly, K.T.; Donnelly, J.P.; Dunnam, M.; Warner, G.; Kittleson, C.J.; Bradshaw, C.B.; Alt, M.; Meier, S.T. Psychometric study of the Neurobehavioral Symptom Inventory. J. Rehabil. Res. Dev. 2012, 49, 879-888. [CrossRef] [PubMed]

20. Medvedev, O.N.; Theadom, A.; Barker-Collo, S.; Feigin, V. Distinguishing between enduring and dynamic concussion symptoms: Applying Generalisability theory to the Rivermead Post Concussion Symptoms Questionnaire (RPQ). PeerJ 2018, 6, e5676. [CrossRef] [PubMed]

21. Geiss, G.K.; Bumgarner, R.E.; Birditt, B.; Dahl, T.; Dowidar, N.; Dunaway, D.L.; Fell, H.P.; Ferree, S.; George, R.D.; Grogan, T.; et al Direct multiplexed measurement of gene expression with color-coded probe pairs. Nat. Biotechnol. 2008, 26, 317-325. [CrossRef]

22. Wienholds, E.; Plasterk, R.H.A. MicroRNA function in animal development. FEBS Lett. 2005, 579, 5911-5922. [CrossRef] [PubMed]

23. Sulhan, S.; Lyon, K.A.; Shapiro, L.A.; Huang, J.H. Neuroinflammation and blood-brain barrier disruption following traumatic brain injury: Pathophysiology and potential therapeutic targets. J. Neurosci. Res. 2020, 98, 19-28. [CrossRef]

24. Zacchigna, S.; Lambrechts, D.; Carmeliet, P. Neurovascular signalling defects in neurodegeneration. Nat. Rev. Neurosci. 2008, 9 , 169-181. [CrossRef] [PubMed]

25. Argandona, E.G.; Bengoetxea, H.; Ortuzar, N.; Bulnes, S.; Rico-Barrio, I.; Vicente Lafuente, J. Vascular Endothelial Growth Factor: Adaptive Changes in the Neuroglialvascular Unit. Curr. Neurovascular Res. 2012, 9, 72-81. [CrossRef] [PubMed]

26. Nasr, I.W.; Chun, Y.; Kannan, S. Neuroimmune responses in the developing brain following traumatic brain injury. Exp. Neurol. 2019, 320, 112957. [CrossRef]

27. Edwards, K.A.; Pattinson, C.L.; Guedes, V.A.; Peyer, J.; Moore, C.; Davis, T.; Devoto, C.; Turtzo, L.C.; Latour, L.; Gill, J.M Inflammatory Cytokines Associate With Neuroimaging After Acute Mild Traumatic Brain Injury. Front. Neurol. 2020, 11, 348. [CrossRef]

28. Johnson, V.E.; Stewart, J.E.; Begbie, F.D.; Trojanowski, J.Q.; Smith, D.H.; Stewart, W. Inflammation and white matter degeneration persist for years after a single traumatic brain injury. Brain 2013, 136, 28-42. [CrossRef] [PubMed]

29. Loane, D.J.; Kumar, A.; Stoica, B.A.; Cabatbat, R.; Faden, A.I. Progressive neurodegeneration after experimental brain trauma: Association with chronic microglial activation. J. Neuropathol. Exp. Neurol. 2014, 73, 14-29. [CrossRef] [PubMed]

30. Scott, G.; Zetterberg, H.; Jolly, A.; Cole, J.H.; De Simoni, S.; Jenkins, P.O.; Feeney, C.; Owen, D.R.; Lingford-Hughes, A.; Howes, O.; et al. Minocycline reduces chronic microglial activation after brain trauma but increases neurodegeneration. Brain 2018, 141, 459-471. [CrossRef] [PubMed]

31. Kim, J.; Krichevsky, A.; Grad, Y.; Hayes, G.D.; Kosik, K.S.; Church, G.M.; Ruvkun, G. Identification of many microRNAs that copurify with polyribosomes in mammalian neurons. Proc. Natl. Acad. Sci. USA 2004, 101, 360-365. [CrossRef] [PubMed]

32. Chaban, V.; Clarke, G.J.B.; Skandsen, T.; Islam, R.; Einarsen, C.E.; Vik, A.; Damås, J.K.; Mollnes, T.E.; Håberg, A.K.; Pischke, S.E Systemic Inflammation Persists the First Year after Mild Traumatic Brain Injury: Results from the Prospective Trondheim Mild Traumatic Brain Injury Study. J. Neurotrauma 2020, 37, 2120-2130. [CrossRef]

33. Benigni, M.; Ricci, C.; Jones, A.R.; Giannini, F.; Al-Chalabi, A.; Battistini, S. Identification of miRNAs as Potential Biomarkers in Cerebrospinal Fluid from Amyotrophic Lateral Sclerosis Patients. Neuromol. Med. 2016, 18, 551-560. [CrossRef] [PubMed] 
34. Joilin, G.; Leigh, P.N.; Newbury, S.F.; Hafezparast, M. An Overview of MicroRNAs as Biomarkers of ALS. Front. Neurol. 2019, 10, 186. [CrossRef]

35. Wang, W.X.; Visavadiya, N.P.; Pandya, J.D.; Nelson, P.T.; Sullivan, P.G.; Springer, J.E. Mitochondria-associated microRNAs in rat hippocampus following traumatic brain injury. Exp. Neurol. 2015, 265, 84-93. [CrossRef] [PubMed]

36. Landgraf, P.; Rusu, M.; Sheridan, R.; Sewer, A.; Iovino, N.; Aravin, A.; Pfeffer, S.; Rice, A.; Kamphorst, A.O.; Landthaler, M.; et al. A Mammalian microRNA Expression Atlas Based on Small RNA Library Sequencing. Cell 2007, 129, 1401-1414. [CrossRef] [PubMed]

37. Sonkoly, E.; Ståhle, M.; Pivarcsi, A. MicroRNAs and immunity: Novel players in the regulation of normal immune function and inflammation. Semin. Cancer Biol. 2008, 18, 131-140. [CrossRef] [PubMed]

38. Deneen, B.; Ho, R.; Lukaszewicz, A.; Hochstim, C.J.; Gronostajski, R.M.; Anderson, D.J. The Transcription Factor NFIA Controls the Onset of Gliogenesis in the Developing Spinal Cord. Neuron 2006, 52, 953-968. [CrossRef] [PubMed]

39. Huang, A.Y.S.; Woo, J.; Sardar, D.; Lozzi, B.; Bosquez Huerta, N.A.; Lin, C.C.J.; Felice, D.; Jain, A.; Paulucci-Holthauzen, A.; Deneen, B. Region-Specific Transcriptional Control of Astrocyte Function Oversees Local Circuit Activities. Neuron 2020, 106, 992-1008. [CrossRef] [PubMed]

40. Guerriero, R.M.; Giza, C.C.; Rotenberg, A. Glutamate and GABA Imbalance Following Traumatic Brain Injury. Curr. Neurol. Neurosci. Rep. 2015, 15, 27. [CrossRef]

41. Drexel, M.; Puhakka, N.; Kirchmair, E.; Hörtnagl, H.; Pitkänen, A.; Sperk, G. Expression of GABA receptor subunits in the hippocampus and thalamus after experimental traumatic brain injury. Neuropharmacology 2015, 88, 122-133. [CrossRef] [PubMed]

42. Yuan, H.; Low, C.M.; Moody, O.A.; Jenkins, A.; Traynelis, S.F. Ionotropic GABA and glutamate receptor mutations and human neurologic diseases. Mol. Pharmacol. 2015, 88, 203-217. [CrossRef]

43. Sheinerman, K.S.; Toledo, J.B.; Tsivinsky, V.G.; Irwin, D.; Grossman, M.; Weintraub, D.; Hurtig, H.I.; Chen-Plotkin, A.; Wolk, D.A.; McCluskey, L.F.; et al. Circulating brain-enriched microRNAs as novel biomarkers for detection and differentiation of neurodegenerative diseases. Alzheimer's Res. Ther. 2017, 9, 89. [CrossRef] [PubMed]

44. Rokad, D.; Ghaisas, S.; Harischandra, D.S.; Jin, H.; Anantharam, V.; Kanthasamy, A.; Kanthasamy, A.G. Role of neurotoxicants and traumatic brain injury in $\alpha$-synuclein protein misfolding and aggregation. Brain Res. Bull. 2017, 133, 60-70. [CrossRef] [PubMed]

45. Goedert, M. Alpha-synuclein and neurodegenerative diseases. Nat. Rev. Neurosci. 2001, 2, 492-501. [CrossRef] [PubMed]

46. Acosta, S.A.; Tajiri, N.; de la Pena, I.; Bastawrous, M.; Sanberg, P.R.; Kaneko, Y.; Borlongan, C.V. Alpha-Synuclein as a pathological link between chronic traumatic brain injury and parkinson's disease. J. Cell. Physiol. 2015, 230, 1024-1032. [CrossRef] [PubMed]

47. Ninkina, N.; Peters, O.; Millership, S.; Salem, H.; van der Putten, H.; Buchman, V.L. $\gamma$-Synucleinopathy: Neurodegeneration associated with overexpression of the mouse protein. Hum. Mol. Genet. 2009, 18, 1779-1794. [CrossRef]

48. Surgucheva, I.; He, S.; Rich, M.C.; Sharma, R.; Ninkina, N.N.; Stahel, P.F.; Surguchov, A. Role of synucleins in traumatic brain injury-An experimental in vitro and in vivo study in mice. Mol. Cell. Neurosci. 2014, 63, 114-123. [CrossRef] [PubMed]

49. Winder, A.D.; Maniar, K.P.; Wei, J.J.; Liu, D.; Scholtens, D.M.; Lurain, J.R.; Schink, J.C.; Buttin, B.M.; Filiaci, V.L.; Lankes, H.A.; et al. Synuclein- $\gamma$ in uterine serous carcinoma impacts survival: An NRG Oncology/Gynecologic Oncology Group study. Cancer 2017, 123, 1144-1155. [CrossRef]

50. Wang, W.X.; Rajeev, B.W.; Stromberg, A.J.; Ren, N.; Tang, G.; Huang, Q.; Rigoutsos, I.; Nelson, P.T. The expression of microRNA miR-107 decreases early in Alzheimer's disease and may accelerate disease progression through regulation of $\beta$-site amyloid precursor protein-cleaving enzyme 1. J. Neurosci. 2008, 28, 1213-1223. [CrossRef]

51. Zhao, J.; Fu, Y.; Yasvoina, M.; Shao, P.; Hitt, B.; O’Connor, T.; Logan, S.; Maus, E.; Citron, M.; Berry, R.; et al. $\beta$-site amyloid precursor protein cleaving enzyme 1 levels become elevated in neurons around amyloid plaques: Implications for Alzheimer's disease pathogenesis. J. Neurosci. 2007, 27, 3639-3649. [CrossRef]

52. Guedes, V.A.; Kenney, K.; Shahim, P.; Qu, B.X.; Lai, C.; Devoto, C.; Walker, W.C.; Nolen, T.; Diaz-Arrastia, R.; Gill, J.M. Exosomal neurofilament light: A prognostic biomarker for remote symptoms after mild traumatic brain injury? Neurology 2020, 94, e2412-e2423. [CrossRef] 